\title{
Neonatal COVID-19: a clinical case report from the Democratic Republic of Congo (DRC)
}

Serge ZIGABE ( $\sim$ sergezigabe@gmail.com )

Universite Catholique de Bukavu Faculte de Medecine

\section{Etienne Kajibwami}

Universite Catholique de Bukavu

\section{Guy-Quesney Mateso}

Universite Catholique de Bukavu

\section{Benjamin Ntaligeza}

Universite Catholique de Bukavu

\section{Case Report}

Keywords: COVID-19, Medecine

Posted Date: August 4th, 2020

DOI: https://doi.org/10.21203/rs.3.rs-51061/v1

License: (c) (i) This work is licensed under a Creative Commons Attribution 4.0 International License. Read Full License 


\section{Abstract}

COVID-19 started as a cluster of pneumonia cases in Wuhan City, the Province of Hubei, China, in December 2019. It spread to many regions of China, outside of China and was declared a pandemic by the World Health Organization (WHO) on March $11^{\text {th }}, 2020$. Initially Africa had no case and now the continent is reporting an increasing number of confirmed cases in an exponential manner $(1,2)$.

\section{Background}

COVID-19 started as a cluster of pneumonia cases in Wuhan City, the Province of Hubei, China, in December 2019. It spread to many regions of China, outside of China and was declared a pandemic by the World Health Organization (WHO) on March $11^{\text {th }}, 2020$. Initially Africa had no case and now the continent is reporting an increasing number of confirmed cases in an exponential manner $(1,2)$.

As of June $17^{\text {th }}, 2020$, there were 187625 confirmed cases with 76334 deaths $(2.32 \%$ case fatality rate [CFR]) reported in the WHO Africa region. South Africa remains the most affected country with 76,334 confirmed cases including 1625 deaths (CFR 2.13\%) (3).

DR Congo, in addition to measles, faces two deadly epidemics: on the one hand Ebola Virus Disease (EVD) with an overall CFR of 66\% (2251/3444) and 64\% (2128/3310) among confirmed cases. On the other hand, COVID-19 disease with 4973 confirmed cases including 111 deaths (CFR 2.23\%) (3). Among the most affected provinces, South Kivu comes third with 108 cases confirmed after Kinshasa (4604 cases) and Central Kongo (249 cases) as of June $17^{\text {th }}, 2020$.

The density of the population, the large internal displacements of the populations, the weakened health system, the weak commitment of political actors, the reluctance of the community, the movements of the populations in the border regions as well as insecurity are all challenges hindering an effective epidemic response.

Pregnant women are a risk group because of the immune adaptations over the entire course of pregnancy (4). In China, a group of pregnant women and their subsequent newborns followed up for SARS-CoV-2 pneumonia presented a number of complications including: fetal distress, premature birth, neonatal distress, thrombocytopenia accompanied by hepatic dysfunction, septicemia as well as neonatal death $(5,6)$.

However, vertical transmission (in utero, in intrapartum or postnatally through breastfeeding) of SARSCoV-2 is possible but not yet confirmed (7-9).

Here we report the first case of COVID-19 in a newborn in the South Kivu province of DRC.

\section{Case Presentation}


Newborn from a 25-year-old mother, gravida 3, para 2 (G3 P2); 34 weeks of gestation with no history of chronic conditions (diabetes, high blood pressure, obesity or asthma). The urogenital infections had not been documented but she had presented fever measured between $39^{\circ}$ and $40^{\circ} \mathrm{C}$.

Her husband was listed as a contact with a confirmed case of COVID-19 in the town of Bukavu in South Kivu. The nasopharyngeal swabs for SARS-CoV-2 RT-PCR taken from the mother were confirmed positive by the national laboratory (INRB-Kinshasa).

She was referred by the medical team from the COVID-19 isolation center where she had been staying for 7 days for the management of a threat of premature delivery in a background of coronavirus disease. Treatments received: antibiotic therapy, tocolysis and administration of dexamethasone for pulmonary maturation of the fetus.

The delivery took place by cesarean section in an operating room. There was a barrier between the mother and the medical team; she was wearing a surgical mask and the medical team wore personnel protective equipment ( sterile gowns,N95 mask, face shields and sterile gloves). The newborn was female, Agpar score 9 at 1 minute and 10 at 5 minutes; weighing $1760 \mathrm{~g}$, measuring $44 \mathrm{~cm}$ in size and 30 $\mathrm{cm}$ in cranial perimeter. The mother did not hold the baby of delivery; usual care were performed for the newborn (wipe and drying the skin, stimulation, administration of vitamin K1, eyes and cord care).

Immediately after birth a blood sample was drown for SARS-COV-2 serological testing; The IgG and IgM returned negative. The nasopharyngeal swabs for the SARS-CoV-2 RT- PCR was sent to the laboratory of the INRB-Kinshasa. A gastric survey was carried out, the swabs (ear, umbilical cord) as well as blood cultures were taken. The newborn was isolated with her mother in a personal room according to the recommendations for the care of the newborn in the context of an epidemic coronavirus (10-13).

The mother hold the newborn, 48 hours after birth, only for breastfeeding and was wearing a surgical mask. The medical team wore personal protective equipment (disposable gowns, surgical mask, sterile gloves) before entering the room. The newborn had good temperature and blood sugar control. In terms of respiratory functions, the newborn was autonomous.

Probabilistic antibiotic prophylaxis combining Penicillin G to Amikacin was prescribed.

The initial kinetics of CRP ( $<3 \mathrm{mg} / \mathrm{L}$ at $\mathrm{HO}-\mathrm{H} 24)$ with procalcitonin (PCT $0.47 \mathrm{ng} / \mathrm{ml})$; anemia $(\mathrm{Hb} 9.7 \mathrm{~g}$ / dL and HCT 25.8\%) with normal platelet count. On the third day of follow-up the newborn developed jaundice (BT $30.29 \mathrm{mg} / \mathrm{dl}$; BD 1.47mg/ dl); severe respiratory distress; axial hypotonia; bloating with abdominal tenderness; gastric residues ( $>50 \%$ ) consisting of undigested milk; thrombocytopenia(112.000/microliter); CRP $26.24 \mathrm{mg} / \mathrm{L}$; Procalcitonin> $100 \mathrm{ng} / \mathrm{mL}$. The diagnoses of neonatal jaundice and ulcerative enterocolitis were retained. Phototherapy was indicated for a period of 72 hours and the newborn was put on oxygen for an oxygen saturation $>92 \%$.

The gastric fluid cultures have isolated Citrobacter sp and Enterobacter Cloacae. Antibiotic therapy combining Meropenem and Vancomycin was initiated to replace the initially prescribed Penicillin $\mathrm{G}$ and 
Amikacin as per the antibiogram. The nasopharyngeal swab for SARS-CoV-2 RT-PCR returned positive. The outcome was death after 5 days of follow-up.

\section{Discussion And Conclusions}

The conditions for optimal management of prematurity are not met in our environment.

However the complications developed by the newborn cannot be attributed solely to prematurity. Intrauterine contamination is less likely given the negative IgG and IgM for SARS-CoV-2 in the newborn immediately after birth; this may have taken place in the perinatal period. The early onset of sepsis, the medical complications and the outcome may have been favored by the SARS-CoV-2 disease background.

COVID-19 perinatal infection can lead to harmful complications in the newborn.

Vertical transmission from mother to fetus is possible but not yet confirmed, however preventive measures must be scrupulously observed in order to limit transmission during the perinatal period. Pediatricians must be associated with the reception and follow-up of newborn babies of mothers infected with COVID-19 to prevent complications in the neonatal period linked to coronavirus disease.

\section{Declarations}

\section{Ethics approval and consent to participate}

All patients admitted in the "Hôpital Provincial Général de Référence de Bukavu” consent that their clinical and imaging data can be used for publication or education purpose.

All procedures performed were in accordance with the ethical standards of the institutional ethical committee and with the 1964 Helsinki declaration and its later amendments.

All patients admitted consent that their clinical and imaging data can be used for publication or education purpose.

\section{Consent for publication}

Written informed consent for publication of the clinical details and/or laboratory results was obtained from the patients or the parents (for the newborn).

\section{Availability of data and materials}

All data generated or analysed during this study are included in this manuscript

\section{Competing interests}

The authors declare that they have no competing interests 


\section{Funding}

There was no funding source for this study

\section{Authors' contributions}

All authors contributed to the study conception and design. All authors contributed to the literature search. The first draft of the manuscript was written by SZ and all authors contributed to subsequent versions of the manuscript. All authors read and approved the final manuscript.

\section{References}

1. Li Q, Guan X, Wu P, Wang X, Zhou L, Tong Y, et al. Early transmission dynamics in Wuhan, China, of novel coronavirus-infected pneumonia. N Engl J Med. 2020;382(13):1199-207.

2. Kolifarhood G, Aghaali M, Saadati HM, Taherpour N, Rahimi S, Izadi N, et al. Epidemiological and Clinical Aspects of COVID-19; a Narrative Review. Arch Acad Emerg Med [Internet]. 2020;8(1):41. Available from: http://journals.sbmu.ac.ir/aaem

3. Coronavirus disease (COVID-19) Situation Report - 149 [Internet]. [cited 2020 Jul 21]. Available from: https://www.who.int/docs/default-source/coronaviruse/situation-reports/20200617-covid-19-sitrep149.pdf?sfvrsn=3b3137b0_8

4. Aghaeepour N, Ganio EA, Mcilwain D, Tsai AS, Tingle M, Van Gassen S, et al. An immune clock of human pregnancy. Sci Immunol. 2017;2(15):1-12.

5. Zhu H, Wang L, Fang C, Peng S, Zhang L, Chang G, et al. Clinical analysis of 10 neonates born to mothers with 2019-nCoV pneumonia. Transl Pediatr. 2020;9(1):51-60.

6. Zeng L, Xia S, Yuan W, Yan K, Xiao F, Shao J, et al. Neonatal Early-Onset Infection with SARS-CoV-2 in 33 Neonates Born to Mothers with COVID-19 in Wuhan, China. JAMA Pediatr. 2020;23(77):2-4.

7. Dong L, Tian J, He S, Zhu C, Wang J, Liu C, et al. Possible Vertical Transmission of SARS-CoV-2 from an Infected Mother to Her Newborn. JAMA - J Am Med Assoc. 2020;323(18):1846-8.

8. Simões e Silva AC, Leal CRV. Is SARS-CoV-2 Vertically Transmitted? Front Pediatr. 2020;8(May):1-5.

9. Lackey KA, Pace RM, Williams JE, Bode L, Donovan SM, Järvinen KM, et al. SARS-CoV-2 and human milk: What is the evidence? Matern Child Nutr. 2020;(May):1-12.

10. Lu Q, Shi Y. Coronavirus disease (COVID-19) and neonate: What neonatologist need to know. J Med Virol. 2020;92(6):564-7.

11. Sonja A R, John C. S, John A. L, Tony S. W, Denise J J. Coronavirus Disease 2019 (COVID-19) and pregnancy: what obstetricians need to know. Am J Obstet Gynecol. 2020;222(5):415-26.

12. Coronavirus (COVID-19) infection and pregnancy [Internet]. [cited 2020 Jul 21]. Available from: https://www.rcog.org.uk/coronavirus-pregnancy

13. Coronavirus Disease 2019 (COVID-19) I CDC [Internet]. [cited 2020 Jul 21]. Available from: https://www.cdc.gov/coronavirus/2019-ncov/ 